\title{
O Ensino Da EJA Nos Anos Iniciais: Dificuldades e Possibilidades
}

\author{
La enseñanza de la educación de jóvenes y adultos en los años iniciales: \\ Dificultades y posibilidades
}

\author{
The teaching of youth and adult education in the early years: Difficulty \\ and possibilities
}

\author{
Camila Corrêa Pierzckalski ${ }^{1}$ \\ Renata Behling ${ }^{2}$ \\ Lígia Cardoso Carlos $^{3}$
}

\begin{abstract}
Resumo
No trabalho apresentamos e discutimos propostas de ensino para a Educação de Jovens e Adultos (EJA) anos iniciais em uma perspectiva de valorização da oralidade e dos conhecimentos empíricos dos alunos, considerando práticas de alfabetização que levem à criticidade. Propomos usar o "senso comum" como ponto de partida para um trabalho baseado nas experiências dos alunos, sem ignorar que essas pessoas já possuem conhecimentos antes de buscar a escola e que estes são estimados. A partir das teorias de Paulo Freire e de Boaventura de Sousa Santos, busca-se proporcionar uma educação politizada, contextualizada, transformadora da realidade e, principalmente, amorosa. Tendo em vista nossa prática de observação, os estágios concomitantes no curso de Licenciatura em Pedagogia da Universidade Federal de Pelotas no estado do Rio Grande do Sul (BR), encontramos nas escolas ações pedagógicas de infantilização e o uso de materiais didáticos pensados a partir de uma psicologia do desenvolvimento infantil, sem considerar a complexidade do mundo adulto. É necessário que as metodologias de alfabetização e letramento presentes na EJA sejam direcionadas para o público que atendem, pois entendemos que a descontextualização é promotora da evasão encontrada nesta modalidade de ensino.
\end{abstract}

Palavras-Chave: Alfabetização; Educação; EJA; Propostas De Ensino; Pedagogia.

\section{Resumen}

En el trabajo presentamos y discutimos propuestas de enseñanza para La EJA años iniciales em uma perspectiva de valorizacíon de La oralidad y de los conocimientos empíricos de los alumnos, considerando prácticas de alfabetizacíon que lleven a La criticidad. Proponemos utilizar el "sentido común" como punto de partida para um trabajo basado em lãs experiências de los alumnos, sin ignorar que esas personas ya poseen conocimientos antes de buscar La escuela y que éstos son estimados. A partir de lãs teorias de Paulo Freire y Boaventura de Sousa Santos, se busca proporcionar uma educación politizada, contextualizada, transformadora de la realidad y, principalmente, amorosa. Em vista de nuestra práctica de observación y lãs etapas concomitantes em el curso de licenciatura em Pedagogía de la Universidad Federal de Pelotas a ubicarse em la ciudad de Pelotas, em el estado Del Rio Grande do Sul (Brasil), encontramos em lãs escuelas acciones pedagógicas de infantilización y el uso de materiales didáctios pensados a partir de uma psicología del desarrollo infantil, sin considerar la complejidad Del mundo adulto. Es necesario que lãs metodologias de alfabetización y letramento presentes em la EJA Sean dirigidas AL público que atiendan, pues entendemos que la descontextualización ES promotora de la evasión encontrada em esta modalidad de enseñanza.

\footnotetext{
${ }^{1}$ Licencianda em Pedagogia na Universidade Federal de Pelotas; Pelotas; RS; Brasil; milapierzckalski@gmail.com

${ }^{2}$ Licencianda em Pedagogia na Universidade Federal de Pelotas; Pelotas; RS; Brasil; renaata.behling@hotmail.com

3 Doutora em Educação, Departamento de Ensino da Faculdade de Educação da Universidade Federal de Pelotas; Pelotas; RS; Brasil; ligi@ufpel.edu.br
} 
Palabras claves: Alfabetización; Educación; EJA; Propuestas de Enseñanza; Pedagogía.

\begin{abstract}
In the paper we present and discuss teaching proposals for the initial EJA in a perspective of valuing orality and studensts empirical knowledge, considering literacy practice that lead to criticality. We propose to use "common sense" as a starting point for a work based on the students experiences, without ignoring that these people already have knowledge before they seek school and that they are steemed. From the theories of Paulo Freire and Boaventura de Sousa Santos, we seek to provide a politicized education, contextualized, transforming reality and, above all, loving. Considering our practice and observation and the concomitant stages in the degree course in pedagogy of the Federal University of Pelotas to be located in the city of Pelotas, in the state of Rio Grande do Sul (Brazil), we find in the schools pedagogical actions of infantilization and use of didactic materials thought from a child developmental psychology, without considering the complexity of the adult world. It is necessary that the literacy methodologies present in the EJA be directed to the public they attend, since we understand the descontextualization is a promoter of the evasion in this teaching modality.
\end{abstract}

Keywords: Education; EJA; Literacy; Teaching Proposals; Pedagogy.

\title{
1. Introdução
}

O texto tem sua origem na formação inicial realizada no Curso de Pedagogia da Universidade Federal de Pelotas (UFPel). Diante das exigências acadêmicas, fomos solicitadas a fazer observações em turmas dos anos iniciais, na modalidade de Educação de Jovens e Adultos (EJA), com o propósito de organizar um projeto de ensino a ser desenvolvido no estágio supervisionado e, também, a conhecer e participar nos processos de gestão escolar, através de uma prática de estágio em gestão. Com o desafio posto, convivemos de forma sistemática, durante o primeiro e o segundo semestre letivo do ano de 2018, com o cotidiano de duas escolas públicas localizadas na periferia da cidade de Pelotas - extremo sul do Brasil - e pudemos perceber o distanciamento entre o contexto de vida dos estudantes e as práticas pedagógicas desenvolvidas nas aulas. A partir da experiência pedagógica e investigativa proporcionada pela licenciatura, acrescida da literatura estudada, estabelecemos alguns caminhos teórico-metodológicos para balizar nossa trajetória profissional, os quais trataremos aqui.

\section{Contextualizações das escolas investigadas}

Uma das escolas, denominada escola A, possui 300 alunos matriculados em três turnos de funcionamento. Comporta diversas salas de aula, biblioteca aberta em período diurno e sala de informática com atendimento em todos os turnos. Não apresenta grandes problemas estruturais e passou por algumas reformas e adequações na sua estrutura física recentemente. O mobiliário das salas é novo e em bom estado de conservação. As turmas de EJA funcionam no período da noite, atendem da primeira à sexta etapa do processo de escolarização e possuem 112 alunos matriculados. 
Os funcionários que lidam com as tarefas burocráticas e de manutenção estão sempre atentos e solícitos a tudo que os alunos, professores e equipe diretiva demandam. Os docentes responsáveis pela gestão da escola são bastante proativos, mas, têm dificuldades para lidar com a realidade de infrequência e evasão dos alunos matriculados, principalmente no turno da noite.

Apesar da boa estrutura física e empenho dos profissionais, observamos que uma sistemática de educação descontextualizada e mais convencional era marcante. Os alunos estavam ofuscados nos planejamentos escolares e o modo de abordar os conteúdos na EJA privilegiavam uma prática infantilizadora e segregacionista.

Espaços da escola como a sala de informática eram utilizados, mas, as características plurais dos estudantes e a falta de profissionais específicos limitavam as ações dos educadores, principalmente com alunos em idade mais avançada. Muitas das atividades propostas ficavam inviabilizadas devido à precariedade de recursos físicos e humanos. O que mais pudemos perceber junto às práticas da EJA nesta escola foi o desconhecimento dos cotidianos dos estudantes, suas características e talentos. Desta forma, o que os alunos pensavam sobre a organização da escola, bem como suas impressões pessoais e raciocínios diante dos temas e conteúdos tratados em aula não eram identificados e, consequentemente, considerados.

A escola B, com 600 alunos matriculados, sendo 135 destes na EJA, possui uma grande estrutura física, mas, com problemas nas instalações elétricas. Comporta, além das salas de aula, auditório, refeitório e biblioteca com acervo bastante rico e títulos variados. $\mathrm{O}$ mobiliário é antigo e bastante deteriorado, com exceção do refeitório. Possui duas lousas digitais, uma na sala de informática e outra na sala dos professores, porém, os profissionais pouco as utilizam por falta de conhecimentos técnicos para manuseá-las. A maioria das janelas não possuem vidros e os ventiladores das salas de aula não funcionam. Durante o turno da noite, em que a EJA acontece, somente o pavilhão administrativo e as seis salas de aula utilizadas ficam iluminadas, impedindo que o resto do espaço da escola seja usado.

No geral parece que os profissionais da escola possuem pouco conhecimento sobre os estudantes. As práticas pedagógicas ocorrem de maneira sistemática e mecanizada, reproduzindo o sistema de educação mais convencional. Conforme o projeto pedagógico, a EJA utilizaria o ensino presencial e o a distância no limite de $20 \%$ da carga horária. O que observamos é que isto não ocorre e muito do tempo de aula é despendido assistindo filmes e documentários, os quais muitos alunos afirmam que não são interessantes. Os conteúdos têm pouca ou nenhuma relação com o contexto social e cultural dos estudantes e muitos deles não 
veem perspectivas profissionais a partir do ensino formal. Diante do contexto observado, lembramos de Paulo Freire quando nos alerta que:

\begin{abstract}
Se a estrutura do meu pensamento é a única certa, irrepreensível, não posso escutar quem pensa e elabora seu discurso de outra maneira que não a minha. Nem tampouco escuto quem fala ou escreve fora dos padrões da gramática dominante. E como estar aberto às formas de ser, de pensar, de valorar, consideradas por nós demasiado estranhas e exóticas, de outra cultura? (FREIRE, 2018, p. 118).
\end{abstract}

A realidade dos educandos é mantida fora dos muros também nesta instituição e, por mais que suas pluralidades sejam reconhecidas, não são utilizadas nas metodologias de ensino e no modo de abordar os conteúdos escolares.

Tendo em vista o acompanhamento que fizemos das rotinas das duas instituições públicas de ensino, foi possível identificar semelhanças em suas metodologias de trabalho pedagógico. Ambas estavam marcadas pela descontextualização entre as realidades dos alunos ali presentes e as práticas escolares. Os estudantes eram tratados de forma subalterna, sendo frequentemente infantilizados através das metodologias de trabalho e do modo de abordagem dos conteúdos, tendo suas narrativas geralmente negadas nos planejamentos de âmbito escolar, bem como nas esferas das secretarias municipal e estadual de educação. Outro fenômeno observado foi a falta de entusiasmo dos sujeitos que frequentam as aulas na modalidade EJA. Tudo parece pouco atrativo e por mais que alguns deles sejam assíduos na escola, seus interesses não parecem estar conectados às aulas.

Nossas observações e investigações nas escolas reafirmaram a imagem da EJA como um ensino compensatório, pensado para garantir um documento que provasse a instrução escolástica, não rompendo com construções de mundo ou permitindo a autonomia dos educandos (DI PIERRO, 2005; REIS, 2011; SCHWARTZ, 2013). Práticas desvinculadas da Constituição Brasileira de 1988 a qual afirma que a educação deva ser de qualidade, propiciando o desenvolvimento da cidadania e do conhecimento de direitos.

Outro fator alarmante para nos situarmos nesse contexto é a alta taxa de evasão dessa modalidade, que só enfatiza o quanto essa problemática é muito mais complexa do que imaginamos. Os motivos pelos quais isso ocorre são variados e perpassam as esferas do social, do político e do educacional. Dentre eles a descontextualização da sala de aula com o mundo da vida e do trabalho. Pois,

[...] esses são sujeitos que conhecem temas relacionados ao mundo do trabalho, é preciso considerar que eles não passaram incólumes pela cultura escrita, já que construíram conhecimentos sobre ela, elaboraram hipóteses, através das quais sobreviveram e desenvolveram estratégias de resoluções de problemas de acordo com suas necessidades/desejos pessoais. (SCHWARTZ, 2013, p.64) 
A educação pode ter um caráter transformador e nas experiências de EJA que observamos isso fica limitado às práticas infantilizadoras na alfabetização e ao contínuo distanciamento entre professores e alunos. Atribuímos a situação à desvalorização dos docentes, ao descaso com as estruturas físicas das escolas e ao desgaste da gestão escolar que perde espaço de democracia para a burocracia. Nas palavras de Bastos:

[...] espera-se que o professor se envolva com o planejamento, com o desenvolvimento e criação de estratégias diversificadas de avaliação do processo ensino-aprendizagem; que assuma a execução de contínuas reestruturações curriculares; que execute tarefas burocráticas e ocupe-se com problemas administrativos e disciplinares, e participe de conselhos de classe e colegiados escolares. Prevê-se que o docente estimule os alunos a estudar e que preste atendimento aos que apresentem ritmos diferenciados de aprendizagem, incluindo os de educação especial inseridos em turmas regulares. Também lhe é solicitado que estabeleça novas relações com a comunidade escolar e com os familiares dos alunos; que receba e oriente os pais dos alunos sobre o rendimento escolar de seus filhos; que supervisione o recreio, que acompanhe os alunos no refeitório e até mesmo no transporte escolar (2009, p.15).

Todas essas funções impostas aos professores contribuem para o seu mal-estar. Além de um contexto histórico de desvalorização da profissão, há uma representação na sociedade de desprestígio da profissão. Mesmo compreendendo todos esses processos adversos, não podemos ignorar a existência dos alunos e suas necessidades imediatas. A conformidade ao discurso que prega a ideia de que não há o que fazer é recorrente no espaço escolar. Espaço que entendemos ter potencial de promover a construção do ser social consciente de seu inacabamento e que busca formas de emancipação.

\subsection{Considerações sobre possibilidades de trabalho pedagógico}

A partir do contexto observado e vivenciado, aliado a diálogos com as equipes diretivas, entendemos que ações pedagógicas integradoras e democráticas são mais relevantes para aqueles processos. Visto que a gestão, a organização escolar e a sala de aula englobam "o contexto social e político, a construção de relações sociais mais humanas e justas e a valorização do trabalho coletivo e participativo" (LIBÂNEO, 2012, p. 448).

Nos relatos dos estudantes da EJA pudemos perceber que o motivo principal da falta de sentimento de pertencimento à escola está conectado com a falta de diálogo entre professores e alunos, bem como com a descontextualização entre os conteúdos trabalhados e a vida cotidiana. Nesta perspectiva, entendemos o diálogo como mediador principal das relações humanas, como nos ensinou Freire: 
[...] o diálogo é uma exigência existencial. E, se ele é o encontro em que se solidariza o refletir e o agir de seus sujeitos endereçados ao mundo a ser transformado e humanizado, não pode reduzir-se a um ato de depositar ideias de um sujeito no outro, nem tampouco tornar-se simples troca de ideias a serem consumidas pelos permutantes. (FREIRE, 2018, p.109)

Dessa maneira, elaboramos nossas propostas de estágio voltadas para propiciar espaços de trocas constantes de ideias, nos quais os sujeitos se sentissem pertencentes ao ambiente escolar e que exercessem suas capacidades de expressar opiniões e compartilhar saberes.

Buscando uma perspectiva emancipatória de educação, nos pautamos por políticas e propostas pedagógicas que possibilitassem um ensino e uma aprendizagem vinculados ao contexto social dos estudantes, valorizando seus saberes e compreendendo que todos somos produtos e produtores de cultura, independentemente do nível de escolarização formal. Nesta perspectiva, Paulo Freire (1991, 2018a e 2018b) e Boaventura de Sousa Santos (2007) muito nos ajudaram a compreender e pensar a gestão escolar e, principalmente, a alfabetização de jovens e adultos. Assim, dialogando com Brandão (2003), para os autores indicados anteriormente, a grande imoralidade do mundo é a sobreposição dos interesses de mercado aos interesses humanos. Na educação essa inversão de valores propaga uma lógica excludente e desumanizadora.

Planejamos uma abordagem através da valorização das narrativas dos estudantes e, também, dos gestores, professores e funcionários. Embasamos nossas propostas a partir dos círculos de cultura de Paulo Freire (1991, 2018a; 2018b) e da Ecologia dos Saberes de Boaventura de Sousa Santos (2007), que abordam a necessidade de uma perspectiva onde nenhum saber seja desvalorizado ou diminuído e que as narrativas de cada um sejam estimadas e necessárias na e para a prática pedagógica.

É próprio da natureza da ecologia de saberes constituir-se mediante perguntas constantes e respostas incompletas. Aí reside sua característica de conhecimento prudente. A ecologia de saberes nos capacita a uma visão mais abrangente tanto daquilo que conhecemos como daquilo que não conhecemos, e também nos previne de que aquilo que não sabemos é ignorância nossa e não ignorância em geral. (SANTOS, 2007, p. 94)

Nas aulas da EJA é essencial que se promova a autonomia e a participação efetiva dos estudantes, através das práticas e dos conteúdos a serem desenvolvidos. Acreditamos que a partir dos círculos de cultura há a possibilidade de os sujeitos da comunidade escolar conhecerem e compreenderem as narrativas e o capital cultural de cada um. Conforme nos ensina Freire, 
[...] o sonho que nos anima é democrático e solidário, não é falando aos outros, de cima para baixo, sobretudo, como se fôssemos os portadores da verdade a ser transmitida aos demais, que aprendemos a escutar, mas é escutando que aprendemos a falar com eles. Somente quem escuta paciente e criticamente o outro, fala com ele [...] (FREIRE, 2018, p. 111).

Entendemos aqui por Círculos de Cultura ações pedagógicas baseadas em uma proposta democrática de aprendizagem articulada com os contextos vivenciados pelos sujeitos. Busca uma reciprocidade na relação entre educador e educando e a valorização das diferentes manifestações culturais. Foram idealizados nas experiências de alfabetização de adultos da década de 1960 com grupos de trabalhadores sob a coordenação de um educador e com o objetivo de discutir e compreender assuntos vinculados ao universo dos próprios trabalhadores.

De forma especulativa, pensamos uma proposta para a EJA em que os educandos se reconheçam na sua humanidade, de modo a se retirarem do estado de opressão e virem a ser o novo colonial. "Nesse movimento, o novo colonial é uma metáfora daqueles que entendem que suas experiências de vida ocorrem do outro lado da linha e se rebelam contra isso" (SANTOS, 2007, p. 78).

O que os alunos das escolas investigadas possuíam em comum, além da modalidade de ensino e sua invisibilidade perante a escola, era o fato de todos estarem em situação de vulnerabilidade socioeconômica, de sofrerem os malefícios das violências do mundo e, principalmente, de não se reconhecerem perante uma sociedade que, historicamente, os apaga e transforma-os em estatística.

\section{Valorizando as narrativas e promovendo a autonomia dos educandos}

Ao acompanharmos as aulas e rotinas das escolas pesquisadas, participando das atividades propostas e conversando com os alunos, foi possível perceber o excesso de atividades infantis na explanação de conteúdos para a alfabetização de jovens e adultos. É necessário salientar que o desenvolvimento da criança, muito ligada à ludicidade e à uma perspectiva de apresentação do mundo, não é sustentada quando se trata da alfabetização de jovens e adultos. Estes, que durante um período considerável estão integrados ao universo da cultura escrita, mesmo sem domínio do código escrito, desenvolveram lógicas de existência e são produtores de sua cultura, estão inseridos no mundo do trabalho e possuem uma história de vida mais longa (OLIVEIRA, 1999).

A escola pública ao abrigar uma modalidade como a EJA - que recebe pessoas que não se adaptaram por diversos motivos no ensino formal ou que a ele nunca tiveram acesso - 
com práticas infantis de alfabetização (cruzadinhas, desenhos, textos literários destinados a crianças, etc.), afastam seus estudantes e continuam mantendo desigualdades sociais. Sendo assim, essa contínua prática na EJA de aproveitamento dos materiais das crianças rompe com a responsabilidade social da instituição escolar.

Acreditamos que, ao possibilitar práticas e conteúdos contextualizados e que valorizam as narrativas dos educandos, os educadores promovem a autonomia dos mesmos junto à sua própria interpretação de mundo e do conhecimento científico, sem abandonar suas lógicas de existência e contribuindo para a expansão do campo epistêmico dos alunos.

[...] não posso de maneira alguma, nas minhas relações polítco-pedagógicas com os grupos populares, desconsiderar seu saber de experiência feito. Sua explicação do mundo de que faz parte a compreensão de sua própria existência no mundo. $\mathrm{E}$ isso tudo vem explicitado ou sugerido ou escondido no que chamo de leitura de mundo, que precede sempre a leitura da palavra. (FREIRE, 2018, p. 79)

É necessário salientar que uma perspectiva de educação contextualizada e política parte das narrativas e produções culturais daqueles que, historicamente oprimidos e silenciados, vivenciam a negação constante de sua existência através das práticas escolares. Nosso papel como educadoras é possibilitar um espaço que transgrida essa lógica e promova uma educação que rompa "com o predomínio elitista da cultura, as expressões cultura popular, educação popular e educação de base são colocadas como bem cultural de acesso a todo o povo" (BRANDÃO; FAGUNDES; 2016, p. 92).

Sendo assim, ao relacionar Freire e Santos, percebemos sua aproximação teórica em prol do resgate da legitimidade dos saberes do Sul global, ou seja, aqueles historicamente oprimidos. Santos (2007) expõe que:

A novidade do cosmopolitismo subalterno reside acima de tudo em seu profundo sentido de incompletude, sem, contudo, ambicionar a completude. [...] defende que quanto mais compreensões não-ocidentais forem identificadas mais evidente se tornará o fato de que ainda restam muitas outras formas por identificar, e que as compreensões hibridas - com elementos ocidentais e não ocidentais - são virtualmente infinitas. O pensamento pós-abissal parte da ideia de que a diversidade do mundo é inesgotável e continua desprovida de uma epistemologia adequada, de modo que a diversidade epistemológica do mundo está por ser construída (SANTOS, 2007, p. 84).

É impossível pensar em transgredir qualquer lógica, seja ela educacional ou até mesmo econômica, sem perceber que não podemos viver em um mundo eurocentrado em que nossa educação não acompanha os avanços da globalização e não valoriza a diversidade epistemológica trazida por cada individuo ao adentrar a escola. Porém, fica evidente que não há interesse em reconhecer a "inesgotável diversidade epistemológica do mundo" (SANTOS, 2007, p. 85), quando persistem métodos tradicionais ou bancários. Deste modo, há a 
necessidade emergente de confrontar "a monocultura da ciência moderna com uma ecologia dos saberes" [...] fundada "no reconhecimento da pluralidade de conhecimentos heterogêneos e em interações sustentáveis e dinâmicas entre eles sem comprometer a autonomia" (SANTOS, 2007, p. 85).

A infantilização da EJA não é apenas um reflexo do descaso público para com a educação, mas o descaso de toda uma sociedade para com suas próprias necessidades.

\begin{abstract}
Se, de um lado, não posso me adaptar ou "converter" ao saber ingênuo dos grupos populares, de outro, não posso, se verdadeiramente progressista, impor-lhes arrogantemente meu saber como o verdadeiro. O diálogo em que se vai desafiando o grupo popular a pensar sua história social como a experiência igualmente social de seus membros vai revelando a necessidade de superar certos saberes que, desnudados, vão mostrando sua incompetência para explicar os fatos. Um dos equívocos funestos de militantes políticos de prática messianicamente autoritária foi sempre desconhecer totalmente a compreensão de mundos dos grupos populares. Vendo-se como portadores da verdade salvadora, sua tarefa irrecusável não é propôla, mas impô-la aos grupos populares. (FREIRE, 2018, p.79)
\end{abstract}

Parece um serviço complexo alterar lógicas educacionais que perpassam séculos e que estão na mão de um capital desinteressado nas questões de cunho social, mas, é possível construir espaços de fala e escuta com jovens e adultos que são remanescentes dessa contínua situação de opressão. Os círculos de cultura de Paulo Freire e a ecologia de saberes de Boaventura de Sousa Santos nos instigam como profissionais a investir na valorização das narrativas daqueles que pouco sabem que tem voz e que precisam lutar pelo seu espaço de fala.

Um educador consciente de suas funções sociais percebe a necessidade de ouvir seus alunos, de valorizar suas narrativas, de se mostrar solícito e, a partir disso, problematizar e contribuir com a expansão dos campos de conhecimento para além do empírico sem extinguilo ou desmoralizá-lo. A EJA não é um depósito de excluídos, ali estão pessoas com características distintas e por motivos variados. Não existe fórmula de transformação da realidade a partir da educação se esta não estiver comprometida com suas funções sociais. Segundo Freire:

[...] a educação é uma forma de intervenção no mundo. Intervenção que, além do conhecimento dos conteúdos bem ou mal ensinados e/ou aprendidos, implica tanto o esforço de reprodução da ideologia dominante quanto o seu desmascaramento. Dialética e contraditória, não poderia ser a educação só uma ou só a outra dessas coisas. Nem apenas reprodutora nem apenas desmascaradora da ideologia dominante. (FREIRE, 2018, p. 96) 
A alfabetização de jovens e adultos tem o potencial de contribuir, através da formação, com a construção de uma sociedade menos desigual. Os conteúdos programados pelas secretarias de educação para a modalidade EJA podem ser trabalhados e expandidos conforme a progressão da turma e as necessidades dos alunos, possibilitando sempre o diálogo e a reflexão crítica sobre tudo o que surge nas conversas e que, para um educador observador e investigador do mundo da vida e do trabalho, é material didático, é palavra geradora, é uma grande ecologia de saberes.

\section{4. É possível combater a evasão na EJA?}

Diante do exposto ficam as perguntas: É possível diminuir a evasão na EJA? Superar as lógicas de infantilização contribuiria para a permanência dos alunos na escola? A aproximação entre conteúdos escolares e o cotidiano dos alunos promoveria mais aprendizagens? Não temos respostas, mas, com o pouco realizado na oportunidade que tivemos, ou seja, as rodas de conversas com os alunos, as observações, as reuniões e conversas com os professores e gestores, nos fazem crer que sim.

Muito da evasão ocorre por motivos de cunho social e a escola sozinha não tem poder para mudar, porém, podemos, ano após ano, transformar a realidade social de alguns que vão, aos poucos, ressignificando suas leituras de mundo e promovendo uma pequena transformação social.

A situação emergente da evasão é causada por práticas pedagógicas falhas, perpassam uma questão social e de política pública, mas, ainda, está em nossas mãos repensar nossas metodologias e posturas frente às adversidades do contexto da EJA. Como já afirmado anteriormente, acreditamos que ações integradoras como o círculo de cultura e a ecologia dos saberes sustentam uma prática que se encontra no horizonte e é viável de acontecer, visto que os sujeitos necessitam ter despertado em si o pertencimento para se sentirem incluídos nos processos de aprendizagem. Caminho esse que é lento, político, processual e pedagógico, mas, possível como nas palavras de Paulo Freire (2018, p.75): “O mundo não é. O mundo está sendo. [...] Não sou apenas objeto da história, mas seu sujeito igualmente. No mundo da história, da cultura, da política, constato não para me adaptar, mas para mudar".

\section{Referências}

BRANDÃO, C. R. Entre Paulo e Boaventura: Algumas aproximações entre o saber e a pesquisa/ A pergunta a várias mãos. São Paulo: Editora Cortez, 2003. 
BRANDÃO, C. R.; FAGUNDES, M. C. V. Cultura popular e educação popular: expressões da proposta freiriana para um sistema de educação. Educar em Revista, Curitiba Brasil, n. 61, p.89 - 106, jun./ set. 2016.

BASTOS, J. O mal-estar docente, o adoecimento e as condições de trabalho no exercício do magistério, no ensino fundamental de Betim/ MG 2009. Mestrado em educação - Pontifícia Universidade Católica de Minas Gerais, Belo Horizonte, 2009.

DI PIERRO, M. C. Notas sobre a redefinição da identidade e das políticas públicas de educação de jovens e adultos no Brasil. Educação \& Sociedade, Campinas, v. 26, n. 92, p. 1115-1139, 2005. Disponível em: http://www.cedes.unicamp.br. Acesso em: 20 dez de 2018 ISSN 1678-4626. (Artigo em Periódico Digital)

FREIRE, P. Educação como prática de liberdade. 20. ed. Rio de Janeiro: Paz e Terra, 1991. 149 p. (Obra Completa)

FREIRE, P. Pedagogia do Oprimido - $66^{\circ}$ ed. Rio de Janeiro| São Paulo. Editora Paz e Terra, 2018a.

FREIRE, P. Pedagogia da Autonomia: Saberes necessários à prática educativa. $57^{\circ}$ ed. Rio de Janeiro| São Paulo. Editora Paz e Terra, 2018b.

LIBÂNEO, J. C. Educação Escolar: Politica, estrutura e organização. O sistema de organização e gestão da escola: teoria e prática. 10 ed. São Paulo: Cortez, 2012.

OLIVEIRA, M. K. de. Jovens e adultos como sujeitos de conhecimento e aprendizagem. Revista Brasileira de Educação, n. 12, p.59-73, set-out-nov-dez, 1999. Disponível em: http://anped.tempsite.ws/novo_portal/rbe/rbedigital/RBDE12/RBDE12_06_MARTA_KOHL _DE_OLIVEIRA.pdf. Acesso em 20 dez. 2018. ISSN 1809-449X (Artigo em Periódico Digital)

REIS, R. H. de. A constituição do ser humano: amor - poder - saber na educação/alfabetização de jovens e adultos. Campinas, SP, 2011.

SANTOS, B. S. Para além do pensamento abissal: Das linhas globais a uma ecologia de saberes. Revista Novos Estudos, CEBRAP, 2007.

SCHAWARTZ, S. Alfabetização de Jovens e Adultos - Rio de Janeiro: Editora Vozes, 2013. 